\title{
The Effect and Mechanism of Apoptosis on Hela Cells induced by Artesunate
}

\author{
Guoquan Wang ${ }^{1, \mathrm{a}}, \mathrm{Xu} \mathrm{ChaO}^{\dagger 1,2 \mathrm{~b}}$, Sha $\mathrm{Li}^{1,2 \mathrm{c}}$, Jin Yan ${ }^{1, \mathrm{~d}}$, Zongmiao $\mathrm{Hu}^{1, \mathrm{e}}$, \\ Chenguang Liang ${ }^{1, f}$, Linzhong $\mathrm{Yu}^{* 3, \mathrm{~g}}$, Enhu Zhang ${ }^{* 1, \mathrm{~h}}$
}

1 The College of pharmcy, Shaanxi University of Chinese Medicine, Xianyang, Shaanxi,712046,China

2 The Second Affiliated Hospital of Shaanxi University of Chinese Medicine, Xianyang, Shaanxi,712046,China

3 School of Traditional Chinese Medicine, Southern Medical University, Guangzhou 510515, China

*Authors to whom correspondence should be addressed: Linzhong Yu, Enhu Zhang

†These authors contributed equally to this work.

a email:wgq585@163.com, ${ }^{b}$ email:chaoxu2004@126.com, ${ }^{c}$

email:ak44400444@163.com, ${ }^{\mathrm{d}}$ email:Anne yan0106@163.com,

eemail:yulzh@fimmu.com ,'email:zeh2006@163.com, ${ }^{9}$ email:huzongmiao1991@163.com,

hemail:lcg@163.com

Keywords: mechanism, Apoptosis, Artesunate, Hela.

Abstract: Cytotoxic activity of Artesunate(ART) was determined by MTT assay at various concentrations ranging from 0 to $100 \mu \mathrm{mol} / \mathrm{L}$ on Hela cells. The apoptosis effect of Hela cells treated with ART was observed by a phase contrast microscope. The Apoptosis and its mechanism induced by ART were also studied by real-time PCR (RT-PCR) and Western blot. The results showed that ART has significant proliferation inhibition effect to Hela cells and the $\mathrm{IC}_{50}$ value is $35.4 \mu \mathrm{mol} / \mathrm{L}$ for $24 \mathrm{~h}$. The expression of Bcl-2 decreased and the expression of Caspas-9 and Bid increased in the Hela cells treated with ART at concentrations from 0 to $100 \mu \mathrm{mol} / \mathrm{L}$. These data suggest that the apoptotic effect of ART is mediated through mitochondrial pathway in Hela cells.

\section{Introduction}

In recent years, there is more and more studies showed some physiochemical found in medicinal herbs exert anti-tumorigenic activities by inducing apoptosis of cancer cells. Plant-derived natural products as well as semisynthetic and synthetic analogs contribute significantly to cancer chemotherapy attribute to their inducing apoptosis activity to malignant tumor cells while exerting low toxicity towards normal cells and thus producing lower adverse effects ${ }^{[1,2]}$.

Artesunate (ART) is a semi-synthetic derivative of artemisinin extracted from the Chinese herb Artemisia annua. It is traditionally used as an anti-malarial agent and exhibits potent cytotoxicity activity in clinical case. In addition, ART has demonstrated remarkable anti-tumor activity, presenting a novel candidate for cancer chemotherapy. Subsequently, many studies of ART using in vitro and animal models have confirmed their remarkable capacity to exert broad anti-cancer effects [3].

Recently studies reported ART can be a promising tumor therapy candidate for many types of tumors. It was reported that ART could induce Apoptosis in gastric carcinoma BGC-823 cells through Caspases pathway ${ }^{[4,5]}$. ART has been shown to have a profound cytotoxic action against several tumors, such as Kaposi's sarcoma, hepatocellular carcinoma, non-small cell lung cancer and cervical cancer ${ }^{[6]}$.

The anticancer effects of ART on Hela cells and its mechanism have not been studied. This aim of the study is to analyze the antitumor effect of ART and investigate its underlying mechanisms of apoptosis on Hela cells in vitro. 


\section{Materials and Methods}

\section{Chemicals and reg-eats}

The standard sample of ART was isolated by the authors from Artemisia annua in the Biomedicine \& Pharmacology Key Laboratory of Shaanxi Province, Shaanxi University of Chinese Medicine.The structure characterized with the chemical and spectroscopic methods (1H NMR, 13C NMR and MS) and compared with those reported in the literature ${ }^{[7-9]}$. Purity was evaluated above 99\%(HPLC and spectral analysis).RPMI-1640 medium, 3-[4, 5-Dimethylthiazol-2-yl]-2, 5-diphenyltetrazolium bromide (MTT), dimethylsulfoxide (DMSO) and Antibodies (Bcl-2,Bid , caspase-9 and $\beta$-actin) were all purchased from Sigma Chemical Co., Ltd (St. Louis, MO, USA).

\section{Cell culture}

Human cervical adencarcinoma cell line HeLa purchased from Cell Bank of Type Culture Collection of Chinese Academy of Sciences (Shanghai, China). Cells grown in RPMI-1640 medium supplemented with $10 \%(\mathrm{v} / \mathrm{v})$ heat-inactivated fetal bovine serum (FBS), 100 units $/ \mathrm{ml}$ penicillin and $100 \mu \mathrm{g} / \mathrm{ml}$ streptomycin at $37^{\circ} \mathrm{C}$ in an incubator containing $5 \% \mathrm{CO}_{2}$. Cells in the exponential growth phase used for all experiments.

\section{Cytotoxicity assay in vitro}

Cytotoxicity of ART was assessed by MTT (3-(4,5-dimethylthiazol-2-yl)-2,5-diphenyl tetrazolium bromide) assay. Briefly, $150 \mu \mathrm{l}$ cells suspension seeded in 96 -well flat-bottom microplates $\left(1 \times 10^{4}\right.$ cells/well) and cultured in a humidified incubator for adhesion overnight. Then the cells exposed to ART at various concentrations of $0,25,50$ and $100 \mu \mathrm{mol} / \mathrm{L}$, respectely. $50 \mu 1 \mathrm{MTT}$ solution $(5 \mathrm{mg} / \mathrm{ml}$ in phosphate buffer $\mathrm{pH}$ 7.4) was added to each well and incubated at $37^{\circ} \mathrm{C}$ for 4 hours. Then the medium was removed and $150 \mu \mathrm{L}$ DSO was added to each well to dissolve the blue formazan crystals. The absorbance(A) was measured at $570 \mathrm{~nm}$ by ELx-800 Universal Microplate Reader (BIO-TEK Instruments,USA). The cell inhibition (\%) was calculated by the following formula:

Cell viability $(\%)=1-\left[\left(\mathrm{OD}_{\text {control }}-\mathrm{OD}_{\text {treated }}\right) /\left(\mathrm{OD}_{\text {control }}-\mathrm{OD}_{\text {blank }}\right)\right]$.

\section{The expression of Bcl-2, Bid and caspas 9 by RT-PCR}

Total RNA of ART-treated cells was extracted using TRIZOL ${ }^{\mathrm{TM}}$ reagent (Promega Corporation) according to the supplier's instruction. RNA was quantitated by optical density measurement at 260 and $280 \mathrm{~nm}$ using a spectrophotometer. And then RNA was Reverse-transcribed using Reverse Transcription System (Takara Shuzo, Shiga, Japan). Primers were obtained from Shanghai Sangon Biological Engineering Technology \& Services Co., Ltd (Shanghai, China). An aliquot ( $2 \mu \mathrm{L})$ of RT product was used for PCR amplification in a total volume of $25 \mu \mathrm{L}$. PCR was performed at $95^{\circ} \mathrm{C}$ for $10 \mathrm{~min}$, followed by 40 cycles of amplification at $95^{\circ} \mathrm{C}$ for $30 \mathrm{~s}, 62^{\circ} \mathrm{C}$ for $30 \mathrm{~s}, 72^{\circ} \mathrm{C}$ for $30 \mathrm{~s}$. The relative RNA expression was calculated from three different experiments. The fold-change form RNA relative to U6 was determined by the formula $2^{-\Delta \Delta \mathrm{Ct}}$.

\section{Protein extraction and Western blot analysis}

Hela cells $\left(1 \times 10^{6}\right)$ were seeded in $10-\mathrm{cm}$ dishes, incubated with various concentrations of ART for $24 \mathrm{~h}$. Protein extract from the Hela cells was performed using $0.5 \mathrm{ml}$ RIPA lysis buffer, followed by centrifugation at $13,200 \mathrm{rpm}$ at $4^{\circ} \mathrm{C}$ for $20 \mathrm{~min}$. Equivalent amounts of $100 \mu \mathrm{g}$ protein from total cell lysates were resolved by SDS-PAGE using precast $12.5 \%$ Bis-Tris gradient gels and transferred onto polyvinylidene difluoride (PVDF) membranes. Afterwards, the membrane was blocked with $5 \%(\mathrm{w} / \mathrm{v})$ non-fat dry milk and incubated with primary antibodies against Bcl-2,Bid,caspas-9 and $\beta$-actin overnight at $4^{\circ} \mathrm{C}$. The mixture was incubated with horseradish peroxidase-conjugated specific secondary antibodies for $1 \mathrm{~h}$ at room temperature. After extensive washing with TBS-T, the bands were visualized by enhanced chemiluminescence followed by exposure to autoradiography film.

\section{Results}

\section{Cytotoxicity of ART on Hela cell}

The cytotoxicity of ART upon Hela cells was assessed by the MTT assay. Under the experimental conditions, ART treatment exhibited significant inhibition on the survival of the types of cells in 
dose-dependent manners. The $\mathrm{IC}_{50}$ values $24 \mathrm{~h}$ was calculated as $35.4 \mu \mathrm{mol} / \mathrm{L}$ for 24 hour in Hela cells (Fig.1).

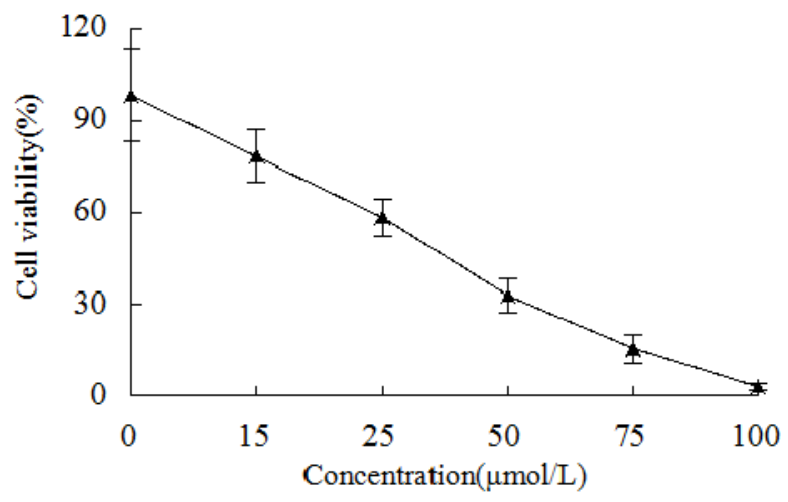

Fig.1 Cytotoxic activities of ART on Hela cells measured by MTT assay.

\section{Apoptosis effect of ART on the cell morphology}

Fig.2 evaluation of inhibition effects on cervical carcinoma Hela cells treated with the ART by microscope. The nuclei of control cells were normal, round and homogeneous. The ART-treated cells exhibited the characteristics of apoptosis, with cell shrinkage, nuclear condensation and fragmentation.

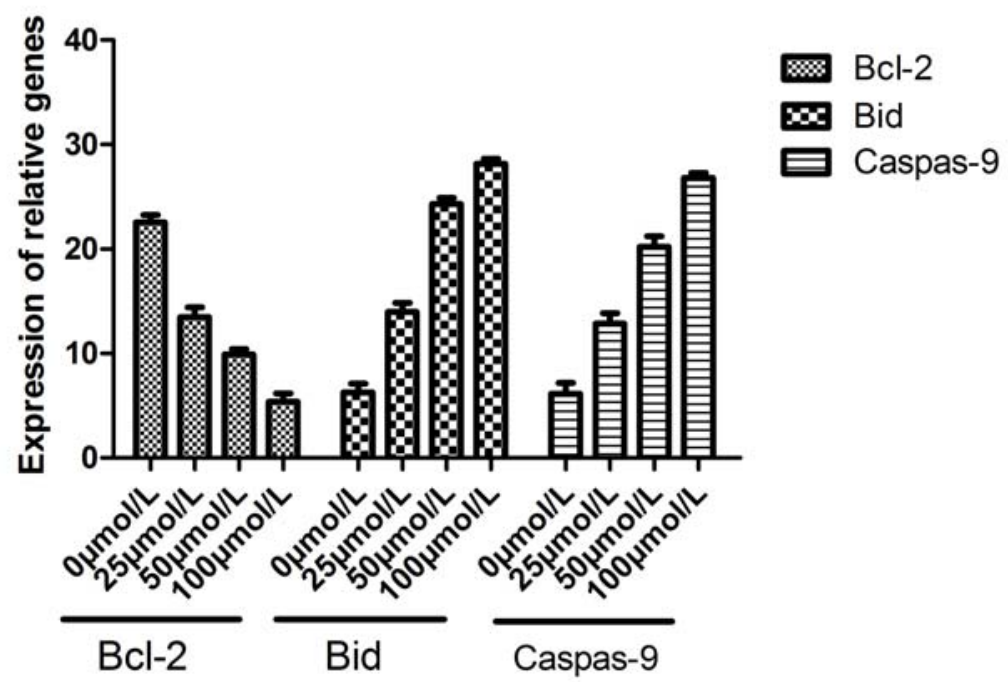

Fig.2 Morphology of HeLa cells treated by ART. HeLa cells were treated with ART at concentrations of $0,25,50$ and $100 \mu \mathrm{mol} / \mathrm{L}$ repectively and observed by a phase contrast microscope. a.Control; b. $25 \mu \mathrm{mol} / \mathrm{L} ;$ c. $50 \mu \mathrm{mol} / \mathrm{L}$; d. $100 \mu \mathrm{mol} / \mathrm{L}$

The expression of Bcl-2,Bid and caspas-9 by RT-PCR

To investigate the mechanism of Apoptosis on Hela cells induced by ART, we mesured the mRNA expression of Bcl-2,Bid and Caspas-9 by RT-PCR. The expression of mRNA of Bcl-2 decreased in the Hela cells treated with ART at concentrations from 0 to $100 \mu \mathrm{mol} / \mathrm{L}$. While the expression of mRNA of Caspas-9 and Bid increased with the concentrations of ART. 


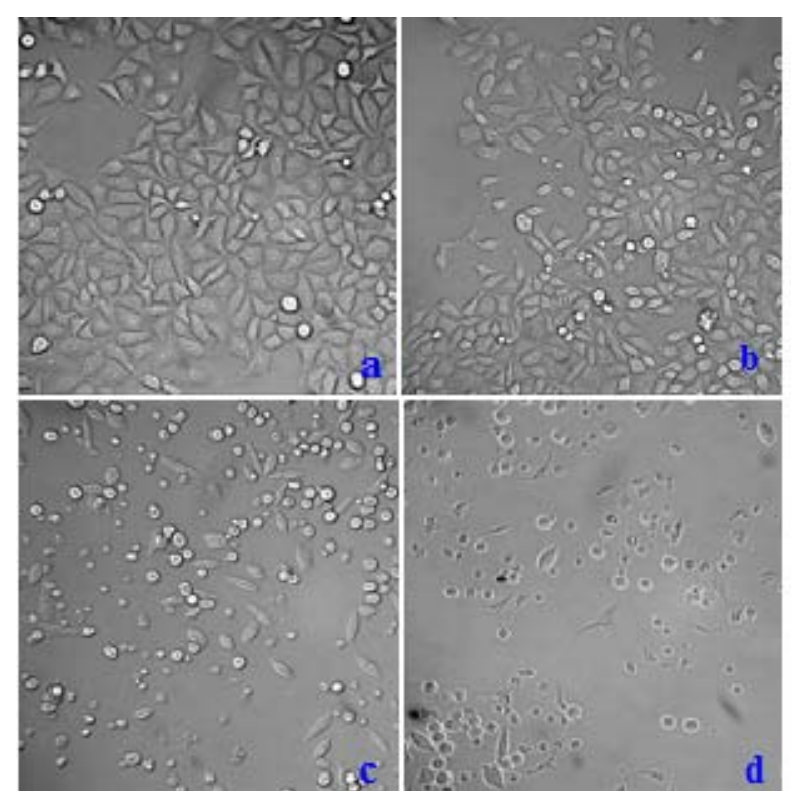

Fig.3 The expression of Bcl-2, Bid and Caspas-9 by RT-PCR.Total RNA of ART-treated cells was extracted and detected by real-time PCR (RT-PCR).

The protein expression of Bcl-2 ,Bid and Caspas-9

To further understand the mechanism of apoptosis induced by ART, we evaluated the protein levels of various key initiators and regulators in the apoptotic pathways through Western blot.The results showed that the ART treatment could reduce the protein level of Bcl-2, whereas the expression level of Bid and Caspase-9 was increased in comparison to the control sample (Fig. 4).
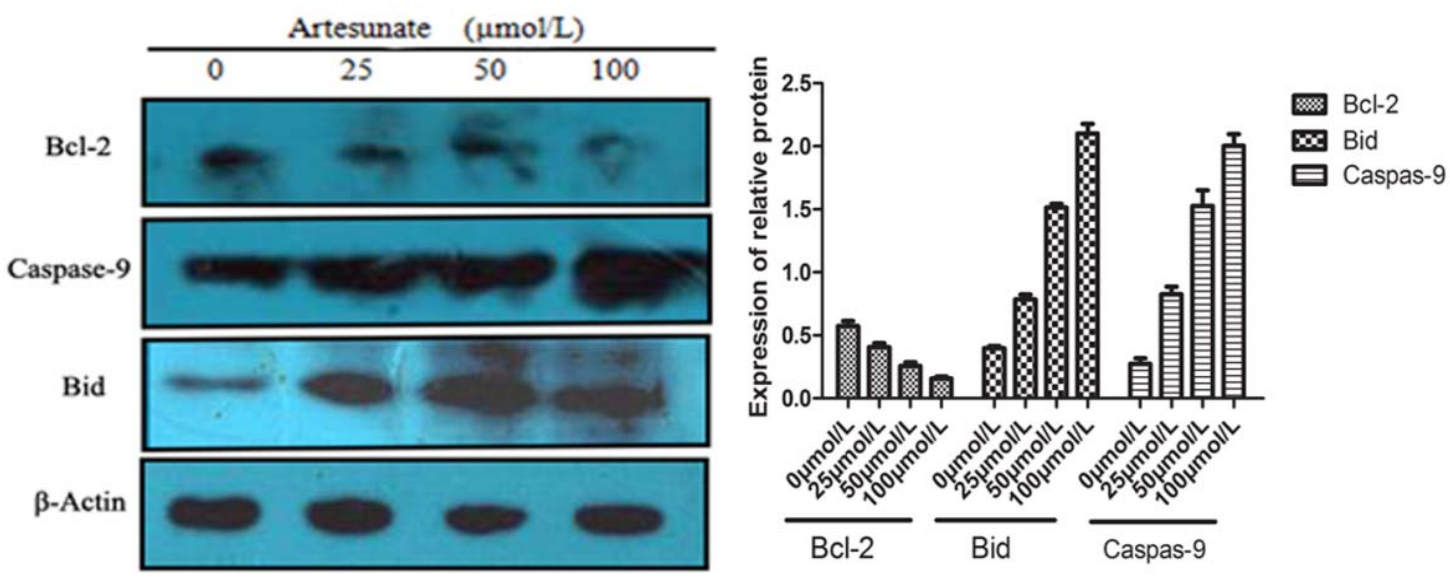

A

Fig. 4 The protein expression of Bcl-2, Bid and Caspas-9 by Western blot. Hela cells were treated with ART at concentrations of $0,25,50$ and $100 \mu \mathrm{mol} / \mathrm{L}$. Then total proteins wer extracted and detected by Western blot.

\section{Conclusions}

ART displays a marked cytotoxicity towards cervical carcinoma HeLa cells. Cell morphology showed ART-treated cells exhibited the characteristics of apoptosis.The expression of Bcl-2 decreased and Caspas-9 and Bid increased in the Hela cells treated with ART with the concentrations increase suggest that the mitochondrial (intrinsic) pathway involved in the ART induced apoptosis pathway. 


\section{Acknowledgements}

The present study was supported by the Scientific Research Program funded by Shaanxi Provincial Science Technology-Department (Program No. 2014JQ4114) and Shaanxi University of Chinese Medicine (Program No. 14XJZR13).

\section{References}

[1] Gullett N.P., Ruhul Amin A.R., Bayraktar S., Pezzuto J.M., Shin D.M., Khuri F.R., Aggarwal B.B., Surh Y.J., Kucuk O. Cancer prevention with natural compounds.[J]Semin Oncol. Vol.37(2010),P.258.

[2] Ichikawa H., Nakamura Y., Kashiwada Y,. Aggarwal B.B. Anticancer drugs designed by mother nature: ancient drugs but modern targets.[J] Curr Pharm Des.Vol.13(2007),P.3400.

[3] Efferth T., Giaisi M., Merling A., Krammer P.H., Li-Weber M. Artesunate induces ROS-mediated apoptosis in doxorubicin-resistant $\mathrm{T}$ leukemia cells. [J]PLoS One.Vol.2(2007),P.e693.

[4] Woerdenbag H.J., Moskal T.A., Pras N., Malingré T.M., El-Feraly F.S., Kampinga H.H.,Antonius W.T.K. Cytotoxicity of artemisinin-related endoperoxides to ehrlich ascites tumor cells. [J]Nat. Prod.Vol..56(1993),P.849.

[5] Dell'Eva R., Pfeffer U., Vené R., Anfosso L., Forlani A., Albini A., Efferth T. Inhibition of angiogenesis invivo and growth of Kaposi's sarcoma xenograft tumors by the anti-malarial artesunate. [J]Biochem. Pharmacol.,Vol..68(2004),P.2359.

[6] Jin M., Shen X., Zhao C., Qin X., Liu H., Huang L., Huang L., Qiu Z., Liu Y. In vivo study of effects of artesunate nanoliposomes on human hepatocellular carcinomaxenografts in nude mice.[J] Drug Deliv. Vol.20(2013),P.127.

[7] Mosmann T. Rapid colorimetric assay for cellular growth and survival: application to proliferation and cytotoxicity assays. [J]Immunol Methods. Vol..65(1983),P.55-63.

[8] Zhang J, Shen Y, Liu J, Wei D. Antimetastatic effect of prodigiosin through inhibition of tumor invasion. [J]Biochem. Pharmacol.Vol.69(2005),P.407.

[9] Man $\mathrm{Wu}$, Yuanzhi Lao, Naihan Xu, et al.Guttiferone $\mathrm{K}$ induces autophagy and sensitizes cancer cells to nutrient stress-induced cell death. [J]Phytomedicine. Vol.22(2015),P.902. 